revista do ieb n 45 p. 37-62 set 2007

\title{
Os vaivéns da rede (internacional) de Capistrano de Abreu'
}

Beatriz Christino ${ }^{2}$

Resumo

Com freqüência, as pesquisas etnográfico-lingüísticas de Capistrano de Abreu foram percebidas como uma extravagância, que consumira inutilmente seu tempo e energia ou como uma espécie de auto-exílio intelectual. 0 presente artigo pretende oferecer um contraponto a essa visão, demonstrando que Capistrano de Abreu foi membro ativo e muito respeitado da comunidade internacional dos especialistas em línguas e culturas da América do Sul no período que vai de 1890 a 1929.

\section{Palavras-chave}

historiografia da lingüística, americanística, Capistrano de Abreu (1853-1927), rã-txa hu-ni-ku-ĩ, caxinauá.

10 presente texto representa um dos frutos de minha pesquisa de doutorado, desenvolvida sob a orientação da Profa. Dra. Cristina Altman (FFLCH-USP) e a co-orientação do Prof. Dr. Mark Münzel (Departamento de Etnografia da Philipps-Universität, Marburg-Alemanha), financiada pela CAPES e pelo convênio CAPES-DAAD.

2 Doutora em Lingüística pela Universidade de São Paulo. 
revista do ieb n 45 p. 37-62 set 2007

\title{
Capistrano de Abreu's international scientific network
}

Beatriz Christino

\begin{abstract}
A few Brazilian historians believed that Capistrano de Abreu wasted his time with his researches about South-American languages. In their opinion, there were almost nobody interested in that subject during the years 1890-1929. This article aims to refuse this idea by showing that Capistrano took part of the main international scientific communities and was considered an expert in that field.
\end{abstract}

\section{Keywords}

linguistic historiography, South-American linguistics,

Capistrano de Abreu (1853-1927), rã-txa hu-ni-ku-ĩ, caxinaua. 
Consegui finalmente apanhar o tipo sintático da língua, um verdadeiro ovo de Colombo, e agora aparece-me em toda a sua unidade através de todas as particularidades. Aos vaivéns da rede, parece-me tudo simples e harmônico. ${ }^{3}$

\section{Em foco, o sul-americanista Capistrano de Abreu}

Capistrano de Abreu (1853-1927), inegavelmente um dos maiores historiadores brasileiros, produziu trabalhos relevantes também nos campos da etnografia e da lingüística. Na realidade, seria inadequado divorciar essas duas dimensões de sua produção intelectual, pois seu interesse pelas línguas e culturas indígenas vinculava-se de modo direto à sua concepção de história. Como afastava-se da corrente, então dominante, que percebia na história do Brasil uma coleção de feitos protagonizados pelos administradores portugueses e julgava que um estudo histórico do nosso país devia dar atenção a todos os elementos formadores da população, Capistrano de Abreu tomava a etnologia ameríndia como uma das faces do trabalho do historiador.

Por longos períodos de sua vida, que abrangem os anos de 1892 e 1895 e, conforme atestam os três volumes de sua correspondência publicada, também entre 1915 e 1927, ele examinou o bacairi, língua da família caribe, então falada nas "cabeceiras do Tapajós e do Xingu em Mato Grosso"4. Parte de suas reflexões provenientes do trabalho com o bacairi veio à luz em 1895 em artigos publicados na Revista Brazileira ${ }^{5}$, dirigida por José Veríssimo (1857-1916). 0 caxinauá, língua da família pano, em uso nas margens do rio Ibuaçu na região do rio Tarauacá, afluente da margem direita do rio Juruá (atual estado do Acre), ocupou-lhe, pelo menos, nos anos de 1908 a 1914. Desse esforço, resultou o rã-txa $h u-n i-k u-\tilde{l}$, composto com o auxílio de dois informantes nativos e publicado em 1914. Principal responsável pela notoriedade atingida por Capistrano de Abreu no campo da

3 Capistrano de Abreu em carta a Pandiá Calógeras, de 28 de setembro de 1910. In: ABREU, João Capistrano de. Correspondência de Capistrano de Abreu. Rio de Janeiro: Ministério da Educação e Cultura, Instituto Nacional do Livro, 1954. v. 1, p. 364.

4 ABREU, João Capistrano de. Os Bacaeris. In: Ensaios e estudos: crítica e história: $3^{a}$ série. Rio de Janeiro: Sociedade Capistrano de Abreu, Livraria Briguiet, 1969. p. 137. $1^{\text {a }}$ edição de 1895.

5 V. Ibid. p. 137-173. 
Sul-americanística, essa obra contém uma seção de descrição gramatical que ocupa da página 11 à 32; uma copiosa recolha de textos totalizando 112 narrativas tradicionais e 66 adivinhações (que se estendem da página 33 à 523); um "Vocabulario brasileiro-caxinauá" que vai da página 524 à 546 e engloba 1781 verbetes e um "Vocabulario caxinauá-brasileiro", disposto entre as páginas 547 e 621 e formado por 4329 verbetes.

Embora Capistrano de Abreu tenha sido eleito sócio-correspondente da Gesellschaft für Anthropologie, Ethnologie und Urgeschichte [Sociedade de Antropologia, Etnologia e Pré-História] de Berlim já em 1895 e seus estudos sobre a língua caxinauá tenham ganho divulgação em periódicos internacionais especializados de prestígio $^{6}$, pouco se investigou acerca da repercussão de sua obra etnográfico-lingüística fora do Brasil. Na realidade, as pesquisas etnográfico-lingüísticas de Capistrano de Abreu foram percebidas, muitas vezes, como uma extravagância, que consumira inutilmente seu tempo e energia, ou como uma espécie de auto-exílio intelectual, que teria lhe ajudado a "olvidar su tristeza personal y la mediocridad que había invadido su ambiente académico" $(\mathrm{p} .147)^{7}$ de historiador. Nesse sentido, Amed declarou

Pode-se dizer que Capistrano tenha reagido mergulhando no interior de um estudo exótico, estéril para a sua época, por conta de não conseguir adequar-se ao seu próprio ambiente intelectual. [...] Ao se deter num estudo abstruso para a sua época, Capistrano parecia constituir uma espécie de justificativa frente ao fato de não conseguir responder aos estímulos intelectuais que percebia em sua atmosfera. ${ }^{8}$

6 cf. RIVET, Paul. Sur quelques dialectes panos peu connus. Journal de la Société des Américanistes de Paris, v. 7, p. 221-242, 1910. p. 223, RIVET, Paul. Bulletin Critique - Capistrano de Abreu (J.). ABREU, João Capistrano de. $r a \tilde{a}-t x a h u-n i-k u-\tilde{\imath}$ - a lingua dos Caxinauás do rio Ibuaçu affluente do Muru (prefeitura de Tarauacá) [rã-txa hu-ní-ku-ĩ, la langue des Caxinauás du rio Ibuaçu, affluent du Muru (préfecture de Tarauacá)], Rio de Janeiro, 1914. v.1, 630 p. Journal de la Société des Américanistes de Paris, v. 11, p. 333, 1914; HESTERMANN, P. Ferdinand. Die Schreibweise der Pano-Vokabularien - mit Benutzung von Angaben J. Capistrano de Abreu's und M. Said Ali Ida's. Journal de la Société des Américanistes de Paris, v. 11, p. 21-33, 1914.

7 BOSCH, Miguel Marín. Hacia una interpretación de la vida y obra del historiador brasileño João Capistrano de Abreu (1853-1927). Latino America, v. 3, p. 141-160, 1970.

8 AMED, Fernando José. As cartas de Capistrano de Abreu: sociabilidade e vida literária na belle époque carioca. São Paulo: Alameda, 2006. p. 220-1. 
Se, de um lado, a investigação de línguas indígenas, naquele momento em nosso país, até poderia ser considerada "um estudo exótico, estéril" por não integrar as preferências dos letrados, no plano internacional, encontrava-se em plena atividade uma comunidade bem articulada de especialistas nas línguas e culturas da América do Sul ${ }^{9}$. Quando se leva em conta o circuito de produção e circulação do saber dessa comunidade de especialistas, fica claro que o sul-americanista Capistrano de Abreu não foi um pesquisador isolado.

\section{0 caráter internacional da Sul-Americanística nos anos 1890-1929}

Para reconstruir o circuito de produção e circulação do conhecimento científico estabelecido pelos sul-americanistas nos anos de 1890 a 1929, recorri a diversos livros e artigos que tinham por tema o estudo de línguas e/ou culturas de povos da América do Sul e cujos autores eram então reconhecidos como especialistas na área. Além disso, fiz uso de documentos pertencentes ao Arquivo Theodor Koch-Grünberg da Philipps-Universität em Marburg (doravante ATKG), ao Arquivo Paul Ehrenreich do Instituto Ibero-Americano de Berlim (doravante APE) e ao Arquivo Capistrano de Abreu (do Instituto Histórico do Ceará em Fortaleza).

Essas fontes revelaram-me uma comunidade de especialistas engajada em um projeto coletivo e internacional de construção do saber. Na documentação analisada, os laços de cooperação científica de pesquisadores europeus (alemães, franceses, suecos e holandeses) entre si e com colegas sul-americanos (brasileiros, argentinos, venezuelanos, chilenos) surgiram com muito mais força do que testemunhos de rivalidades ou de disputas por prestígio.

9 Essa comunidade de especialistas, estabelecida por volta de 1890, fundamentou seus estudos em pesquisas de campo e também nos trabalhos sobre línguas indígenas produzidos pelos missionários dos tempos coloniais e nas informações fornecidas por viajantes, exploradores e naturalistas como o Príncipe Maximilan de Neuwied (1782-1867), Auguste de Saint-Hilaire (1779-1853) e Johann Natterer (1787-1843). 0 botânico Karl Phillip von Martius (17941868), que nos seus Glossaria Linguarum Brasiliensium reuniu dados de 109 línguas e propôs uma classificação para as línguas brasileiras (cf. MARTIUS, Karl Friedrich von. Beiträge zur Ethnographie und Sprachenkunde Amerika's zumal Brasilien. v. II: Wörtersammlung brasilianischer Sprachen, Glossarium linguarum brasiliensium, Glossarios de diversas línguas e dialetos, que fallão os indios do Brazil. Leipzig: Friedrich Fleischer, 1867), tornou-se uma das principais fontes para os sul-americanistas dos anos 1890-1929. 
Textos em alemão no Journal de la Sociètè des Américanistes de Paris ${ }^{10}$, assim como textos em francês na Zeitschrift für Ethnologie ${ }^{11}$, evidenciam o caráter internacional da Sulamericanística daquele momento. Igualam-se, assim, a algumas dedicatórias, como a do alemão Theodor Koch-Grünberg (1872-1924) ao francês Paul Rivet (1876-1958): "Herrn Dr. Paul Rivet zu eigen" [Para que pertença ao Dr. Paul Rivet] ${ }^{12}$; a do sueco Erland Nordenskiöld (1877-1932) a Koch-Grünberg: "Dem berühmten Südamerikaforscher/ Theodor Koch-Grünberg” [Ao ilustre pesquisador da América do Sul/ Theodor Koch-Grünberg] ${ }^{13}$ e a de Koch-Grünberg ${ }^{14}$ a Nordenskiöld: "Dem Freunde der Indianer Erland Nordenskiöld ist dieses Buch gewidmet” [Ao amigo dos índios, Erland Nordenskiöld, é dedicado este livro] ${ }^{15}$.

Deixando-se o terreno das homenagens públicas e focalizando-se o dia-a-dia dos pesquisadores, avultam os registros de intercâmbio de material publicado e/ou inédito entre os sul-americanistas. A troca de separatas consistia em uma forma privilegiada de divulgação dos trabalhos. Pude localizar, na biblioteca pessoal de Capistrano de Abreu, uma separata do Vocabulario Chorote ó Solote, acompanhada de dedicatória do autor - "Al distinguido colega/ Don J. Capistrano de Abreu,/ Robert LehmannNitsche" - e oito separatas de trabalhos de Rivet, contendo um

10 Caso de KOCH-GRÜNBERG, Theodor. Die Uitóto-Indianer. Weitere Beiträge zu ihrer Sprache nach einer Wörterliste von Hermann Schmidt (Manáos, Brasilien). Journal de la Société des Américanistes de Paris, v. 7, p. 61-83, 1910; KOCH-GRÜNBERG, Theodor. Ein Beitrag zur Sprache der Ipuriná-Indianer (Rio Purus, Brasilien). Journal de la Société des Américanistes de Paris, v. 11, p. 57-96, 1914.; HESTERMANN, P. Ferdinand. Zur Transkriptionsfrage des Yagan (Feuerland). Journal de la Société des Américanistes de Paris, v. 10, p. 27-41, 1913 e de HESTERMANN, P. Ferdinand. Die Schreibweise der Pano-Vokabularien - mit Benutzung von Angaben J. Capistrano de Abreu's und M. Said Ali Ida's. Journal de la Société des Américanistes de Paris, v. 11, p. 21-33, 1914.

11 Como RIVET, Paul et H. Beuchat. La famille linguistique Cahuapana. Zeitschrift für Ethnologie, v. 41, p. 616-634, 1909.

12 KOCH-GRÜNBERG, Theodor. Vom Roroima zum Orinoco. Ergebnisse einer Reise in Nordbrasilien und Venezuela in den Jahren 1911-1913. Vierter Band. Sprachen. (Hrsg. von Ferdinand Hestermann). Stuttgart: Strecker und Schröder, 1928. página de rosto.

13 NORDENSKIÖLD, Erland. Forschungen und Abenteuer in Südamerika. Stuttgart: Strecker und Schröder, 1924. página de rosto.

14 KOCH-GRÜNBERG, Theodor. Vom Roroima zum Orinoco. Ergebnisse einer Reise in Nordbrasilien und Venezuela in den Jahren 1911-1913. Erster Band. Schilderung der Reise. Berlin: Dietrich Reimer, 1917. página de rosto.

15 Traduções Beatriz Christino. 
carimbo com os dizeres "Hommage de l'auteur" na capa. Desse conjunto, não fazia parte uma publicação referida na obra de Capistrano de Abreu sobre a língua caxinauá, a “( [...] separata Sur quelques dialectes panos peu connus, que devo á benevolência do autor, a quem sou muito grato)." 16

$\mathrm{Na}$ intenção de divulgar amplamente seus trabalhos e de fomentar a cooperação científica internacional, os sul-americanistas não hesitavam em mandar livros e artigos para pesquisadores com quem nunca dantes haviam travado contato, desde que se pudesse notar um real interesse de parte do destinatário. Como exemplo disso, pode figurar a primeira carta de Teodoro Sampaio (1855-1937) a Koch-Grünberg, em que fica registrado, inclusive, o papel de Capistrano de Abreu na aproximação entre os dois interessados nas línguas brasileiras.

Exmo. Snr. Dr. Th. Koch-Grünberg

Accuso recebidos e muito agradeço a V. Ex. os livros e publicações que me remetteu a proposito de suas viagens no valle do Orenoco e do Amazonas e dos estudos das linguas Aruak e dos indios Uitoto do Japurá, os quaes tinha eu ja visto citados varias vezes e de que me falou ultimamente o nosso eminente amigo, o philologo e historiador, J. Capistrano de Abreu do Rio de Janeiro. 0 estudo das linguas brasilicas a que me tenho dedicado, me levaram [sic] a desejar possuir os trabalhos de V. Exa. sobre os indios do Orenoco e do Amazonas e manifestei esse desejo a Capistrano, a quem decerto devo o conseguir de V. Exa. a remessa alludida. $^{17}$

Pude coletar numerosos exemplos de disponibilização de dados inéditos para colegas de outras partes do mundo. Rivet enviou a P. Wilhelm Schmidt (1868-1954) ${ }^{18}$, alemão radicado na Áustria (onde era editor da importante Anthropos, revista internacional de etnologia e lingüística), as provas de impressão do capítulo sobre as línguas americanas que preparara para a

16 ABREU, João Capistrano de. rã-txa $h u-n i-k u-\tilde{l}$ - a língua dos caxinauás do rio Ibuaçú, affluente do Murú (Prefeitura de Tarauacá). 1.ed. Rio de Janeiro: Typografia Leuzinger, 1914. p. 626.

17 Carta de Teodoro Sampaio a Theodor Koch-Grünberg, de $1^{\circ}$ de agosto de 1914, Série “Correspondência”, Pasta 17, ATKG, sublinhados originais.

18 Embora o missionário católico e pesquisador P. W. Schmidt não tivesse se dedicado exclusivamente ao estudo da lingüística e da etnografia sul-americanas, sua produção nessa área gozava de prestígio e foi publicada tanto de forma independente quanto como parte de tratados de alcance geral sobre lingüística e mitologia. 
obra coletiva Les langues $d u$ monde ${ }^{19}$. Nordenskiöld, por sua vez, forneceu documentação lingüística inédita a Rivet e CréquiMonfort ${ }^{20}$ e uma coleção manuscrita de narrativas Tacána, Baure e Itonáma a Koch-Grünberg ${ }^{21}$. Seguindo a praxe entre os sulamericanistas, o venezuelano Luis Ramón Oramas (1884-1967) escreveu a Koch-Grünberg: "Puedo suministrarle datos, vocabularios inéditos"22. Ciente de que a publicação dos resultados lingüísticos de sua segunda expedição ao Brasil tardaria muito, Koch-Grünberg ofereceu-se para mandar cópias datilografadas dos vocabulários reunidos para Rivet $^{23}$.

Também Capistrano de Abreu não fez segredos acerca de seus trabalhos em andamento. Uma nota de rodapé num artigo de Rivet informa aos leitores: "1. M. J. CAPISTRANO DE ABREU prépare en ce moment un ouvrage sur la langue des Kaxinawás, qui comprendra de nombreuses phrases, des textes, un vocabulaire abondant et une grammaire." (p.223) ${ }^{24}$. Mais do que somente uma notícia de obra em preparação, o lingüista alemão Ferdinand Hestermann (1887-1959) recebeu as primeiras provas do vocabulário caxinauá de Capistrano de $\mathrm{Abreu}^{25}$, fundamentais para a elaboração de seu artigo sobre a forma de transcrição das palavras em vocabulários de línguas pano ${ }^{26}$.

19 Cf. SCHMIDT, P. Wilhelm. Die Sprachfamilien und Sprachenkreise der Erde. Heidelberg: Carl Winter's Universitätshandlung, 1926. p. 210.

20 RIVET, Paul; CREQUI-MONFORT, G. de. Les dialectes Pano de Bolivie. Louvain: J. B. Istas, 1913. RIVET, Paul; CREQUI-MONFORT, G. de. La famille linguistique Takana. Journal de la Société des Américanistes de Paris, v. 13, p. 91-102; 281-301, 1921.

21 KOCH-GRÜNBERG, Theodor. Vom Roroima zum Orinoco, Ergebnisse einer Reise in Nordbrasilien und Venezuela in den Jahren 1911-1913. Zweiter Band. Mythen und Legenden der Taulipang und Arekuna-Indianer. Stuttgart: Strecker und Schröder, Zweite Ausgabe, 1924 [1916].

22 Carta de 16 de janeiro de 1914, Série “Correspondência”, Pasta 15, ATKG.

23 Cf. carta de Theodor Koch-Grünberg a Paul Rivet, datada de $1^{\circ}$ de novembro de 1920, Série “Correspondência”, Pasta 29, ATKG.

24 RIVET, Paul. Sur quelques dialectes panos peu connus. Journal de la Société des Américanistes de Paris, v. 7, p. 221-242, 1910.

25 Cf. carta de Capistrano de Abreu a Mário de Alencar, de 16 de março de 1912 (v. ABREU, João Capistrano de. Correspondência de Capistrano de Abreu. Rio de Janeiro: Ministério da Educação e Cultura, Instituto Nacional do Livro, 1954. v. 1, p. 230-1.)

26 HESTERMANN, P. Ferdinand. Die Schreibweise der Pano-Vokabularien mit Benutzung von Angaben J. Capistrano de Abreu's und M. Said Ali Ida's. Journal de la Société des Américanistes de Paris, v. 11, p. 21-33, 1914. 
Considerada o ideal de conduta científica pelos sul-americanistas do período 1890-1929, a estreita colaboração com colegas de outros países viu-se enormemente dificultada pela Primeira Guerra. Nesse contexto, o fim da guerra representou um momento de se atuar em prol do restabelecimento da cooperação internacional. Koch-Grünberg, por exemplo, procurou resgatar seus contatos científicos na América do Sul, tão logo houve a suspensão do conflito. Um de seus mais importantes interlocutores sul-americanos, Capistrano de Abreu não tardou a receber notícias acerca das atividades científicas de Koch-Grünberg durante a guerra. 0 alemão não descuidou, em sua carta, do intercâmbio de publicações: enviou trabalhos seus a Capistrano de Abreu e pediu que lhe fosse remetido o maior número possível de textos de estudiosos brasileiros. Por conta de seu conteúdo particularmente significativo, permiti-me citar essa carta de forma longa.

Ich freue mich sehr, dass dieser schreckliche Krieg, der so viel Unglück über die Menschheit gebracht hat, endlich vorüber ist, und dass ich jetzt wieder Gelegenheit habe, mit Ihnen in Verbindung zu treten. - Unsere Wissenschaft hat durch den Krieg sehr gelitten, und wir müssen jetzt doppelt arbeiten nachzuholen. Nur durch die internationalen Verbindungen ist dies möglich.

Ihr ausgezeichnetes und in der Südamerika-Forschung wohl einzig dastehendes Werk über die Caxinaua habe ich im letzten Jahr genau studiert. Ich bewundere das riesige, wertvolle Material, das in dem Buch enthalten ist. [...] - Einige Ihrer schönen Mythen habe ich ins Deutsche übersetzt und in meinem demnächst erscheinenden Buch „Südamerikanische Indianermärchen“ zum Abdruck gebracht, wofür ich sie nachträglich um Erlaubnis bitten möchte.

Über die Ergebnisse meiner letzten Reise habe ich bis jetzt zwei Bände meinen Verleger beauftragt, Ihnen die beiden Bände zu schicken, und bitte Sie, die Bücher als ein Zeichen meiner Bewunderung und Verehrung annehmen zu wollen. - Gleichzeitig sende ich Ihnen einige kleinere Arbeiten von mir, die während der letzten Jahre erschienen sind.

Ich wäre Ihnen sehr dankbar, wenn Sie mir alle ethnographischen Arbeiten schicken würden, die seit 1914 in Brasilien erschienen sind, soweit dies möglich ist. 
[Eu muito me alegro que essa terrível guerra, que trouxe tanta infelicidade para a humanidade, finalmente terminou e que eu agora tenho novamente oportunidade de colocar-me em contato com o Sr. - A nossa ciência sofreu muito por conta da guerra e nós agora temos que trabalhar dobrado para recuperar. Somente por meio dos contatos internacionais isso é possivel.

Estudei minuciosamente no ano passado sua excelente obra sobre os caxinauás, realmente singular na pesquisa sobre a América do Sul. Eu admiro o material imenso e valioso, que está contido no livro. [...] Alguns dos seus belos mitos traduzi para o Alemão e serão impressos no meu próximo livro a ser publicado "Südamerikanische Indianermärchen“ [Lendas indigenas sul-americanas ${ }^{27}$ ], pelo que gostaria de pedir-lhe, $a$ posteriori, autorização.

Acerca dos resultados da minha última viagem, incumbi meu editor de enviar-lhe os dois volumes até agora publicados e peço ao Sr. que queira receber os livros como um sinal da minha admiração e de meu respeito. Ao mesmo tempo, envio-lhe alguns trabalhos de minha autoria, de menor extensão, que foram publicados durante os últimos anos.

Eu lhe seria muito grato, se o Sr. me enviasse, na medida do possível, todos os trabalhos etnográficos que foram publicados no Brasil desde 1914$]^{28}$

Como nos leva a inferir essa carta, mesmo com a grave crise por que passava a sua ciência no pós-guerra, os sul-americanistas europeus fizeram o possível para manter-se produtivos e, tão logo tornou-se viável, procuraram retomar a teia internacional de contatos e intercâmbios.

\section{A "última hora" e a necessidade de especialistas}

Quanto mais a realidade dos sertões e das florestas sul-americanas se tornava conhecida pelos cientistas, mais se

270 livro a que aludiu Koch-Grünberg acabou por ser batizado Indianermärchen aus Südamerika [Lendas indígenas da América do Sul], cf. KOCH-GRÜNBERG, Theodor. Indianermärchen aus Südamerika. Jena: Eugen Diedrichs, Zweite Ausgabe, 1927 [1920].

28 Carta de Theodor Koch-Grünberg a Capistrano de Abreu, de 8 de janeiro de 1920, Série “Correspondência”, Pasta 28, ATKG, trad. Beatriz Christino. 
enfraquecia a esperança de encontrar regiões completamente intocadas pelo homem branco. Por isso, ganhavam relevância as informações sobre povos que ainda se mantinham completamente afastados dos modelos europeus de civilização e conservavam como que imaculadas sua língua e suas manifestações culturais. Os sul-americanistas lamentavam que fossem comuns as notícias de grupos indígenas já extintos, em processo de desaparecimento ou severamente atingidos por epidemias ${ }^{29}$. Diante do avanço sempre crescente e devastador da "civilização", aqueles especialistas ressaltavam a necessidade urgente de promover pesquisas lingüísticas e etnográficas sérias. Tratava-se de uma corrida contra o tempo para registrar o que ainda restava das línguas e culturas indígenas, evidenciada pelo freqüente recurso a expressões como "última hora" e "última oportunidade"30.

No estudo intitulado Os Kraôs do Rio Preto no Estado da Bahia, Teodoro Sampaio registrou:

como lingua viva [o Kraô], está bem perto de desaparecer, tão apertado se está tornando de dia para dia o círculo de ferro, em que a civilização encerrou os ultimos sobreviventes desta nação gentia. ${ }^{31}$

Segundo uma carta que endereçou a Sampaio, KochGrünberg tomara conhecimento desse trabalho graças a uma resenha saída no Journal de la Société des Américanistes de Paris $^{32}$. Sua reação à iniciativa do intelectual brasileiro foi entusiástica. Em face da urgência de se estudar os povos indígenas antes de seu total desaparecimento, Koch-Grünberg destacou que

29 V., por exemplo, SCHMIDT, Max. Reisen in Matto Grosso im Jahre 1910. Zeitschrift für Ethnologie, v. 44, p. 130-174, 1912. p. 143; KISSENBERTH, Wilhelm. Über die hauptsächlichsten Ergebnisse der Araguaya-Reise. Zeitschrift für Ethnologie, v. 44, p. 36-59, 1912. p. 52-59.

30 Essas expressões surgem, por exemplo, nas cartas de Theodor KochGrünberg a Curt Nimuendajú (16 de setembro de 1920, 13 de novembro de 1921, 11 de fevereiro e 10 de março de 1924), na carta de Theodor KochGrünberg a seu editor August Schröder datada de 10 março de 1924 e na carta escrita por Fritz Krause em 20 de outubro de 1918 para Koch-Grünberg. Elas se encontram, respectivamente, nas pastas 29, 31, 37 (no caso das três datadas de 1924) e 25 da Série "Correspondência”, ATKG.

31 SAMPAI0, Teodoro. Os krahôs do Rio Preto no Estado da Bahia. Rio de Janeiro: Livraria J. Leite, [c. 1912]. p. 157-8.

32 RIVET, Paul. SAMPAIO (Theodoro). Os Kraôs do Rio Preto no Estado da Bahia. (Les Kraôs du rio Preto dans l'État de Bahia). Revista do Instituto historico e geographico brasileiro, Rio de Janeiro, t. 75, p. 143-205, 1912/1913; Journal de la Société des Américanistes de Paris, v. 10, p. 637-638, 1913. 
seria desejável que outros intelectuais brasileiros seguissem o louvável exemplo do destinatário e de Capistrano de Abreu:

Möchten sich doch in Brasilien nicht viele Gelehrte finden, die sich wie Sie und der trefflicher Dr. J. Cap. de Abreu, dem interessanten Studium der Ureinwohner widmen, bevor es zu spät ist.

[Não se queira, de fato, encontrar no Brasil muitos intelectuais, que, como o Sr. e o excelente Dr. J. Cap. de Abreu se dedicam ao interessante estudo dos habitantes primitivos, antes que seja tarde demais]. ${ }^{33}$

De fato, Capistrano de Abreu também julgava que as investigações acerca das línguas e culturas indígenas não podiam esperar. Sem dar margem a dúvidas, ele justificou porque preferia prosseguir no exame do bacairi, em lugar de escrever uma obra capaz de sistematizar sua produção historiográfica: "Mais importante [que projetos de história] é dar conta dos bacairis: estes vão todos os dias diminuindo; em breve não haverá mais; historiadores tivemos em roldão" ${ }^{34}$. Capistrano de Abreu revelou, ainda, a intenção de investigar a ameaçada língua xavante:

Existe em São Paulo um problema lingüístico, que não sei se ainda será tempo de estudar - o dos xavantes. Já são muito poucos, muito reduzidos os vocabulários [...] Agora encontrei um [...] fazendeiro no Paranapanema; pedi-lhe reunisse uns indios com os quais se poderia tentar alguma cousa. ${ }^{35}$

Noutra carta, Capistrano de Abreu explicitou que a preocupação em registrar a língua dos caxinauás, permitindo que a posteridade tivesse memória de sua existência, levou-o a compor o rã-txa $h u-n i-k u-\tilde{l}$. De acordo com suas palavras, “[o]rganizei-o para não suceder com esta o mesmo que com

33 Carta de Theodor Koch-Grünberg a Teodoro Sampaio, rascunho sem data, Pasta 17, Série "Correspondência”, ATKG, trad. Beatriz Christino.

34 Carta de 25 de setembro de 1922, In: ABREU, João Capistrano de. Correspondência de Capistrano de Abreu. 2.ed. Rio de Janeiro: Civilização Brasileira; Brasília: Instituto Nacional do Livro, 1977. v. 3, p. 90. (1ª edição de 1954).

35 Carta datada de “Oitava de Tiradentes”, 1923. In: ABREU, João Capistrano de. Correspondência de Capistrano de Abreu. Rio de Janeiro: Ministério da Educação e Cultura, Instituto Nacional do Livro, 1954a. v. 2, p. 274. 
uma língua do Orinoco, conservada apenas por um papagaio, afirma Humboldt" ${ }^{36}$.

Não escaparam à percepção dos sul-americanistas as razões que engendravam o declínio constante do contingente de população indígena e a perda sempre mais acentuada de seus traços culturais. Sem partilhar das teorias de desigualdade racial, em voga em outros círculos de intelectuais no período 1890-1929, os sul-americanistas recusavam-se a aceitar que as civilizações não-brancas teriam, sempre que se desse o contato, de sucumbir diante da pretensa superioridade intelectual e cultural dos brancos. Seus textos mostram que o domínio dos brancos fundamentava-se no uso da violência e não nascia de um desejo de divulgar formas mais avançadas de vida em sociedade, mas da intenção de explorar economicamente as terras indígenas. Koch-Grünberg, por exemplo, declarou de maneira contundente: "Die Hauptgründe für das Aussterben der Naturvölker ${ }^{37}$ kann man, meiner Absicht nach in dem einen Wort zusammenfassen: Kapitalismus". [As principais razões da extinção dos 'povos da natureza' podem, na minha concepção, ser resumidas em uma palavra: Capitalismo] ${ }^{38}$.

Tornada item de primeira necessidade pela indústria automobilística, a borracha convertia áreas antes fora da influência do capitalismo internacional em fornecedoras de insumo para um setor de ponta (p.207) ${ }^{39}$. A intensa, acelerada e dramática

36 Carta a Alfredo Pujol, datada de 29 de abril de 1916. In: ABREU, João Capistrano de. Correspondência de Capistrano de Abreu. 2.ed. Rio de Janeiro: Civilização Brasileira; Brasília: Instituto Nacional do Livro, 1977. v. 3, p. 66. (1ª edição de 1954).

$37 \mathrm{Na}$ literatura etnográfica em alemão, durante o período estudado, utilizavase freqüentemente a distinção Naturvölker (povos da natureza) x Kulturvölker (povos da cultura), de modo a marcar o que se percebia como diferentes graus de complexidade da organização social e cultural das civilizações, cf. por ex., o título de STEINEN, Karl von den. Unter den Naturvölkern Zentral-Brasiliens - Reiseschilderung und Ergebnisse der Zweiten SchingúExpedition 1887-1888. Berlin: Dietrich Reimer, 1894.

38 Carta a Karl Sapper, 8 de novembro de 1916, Pasta 21, Série “Correspondência”, ATKG, trad. Beatriz Christino.

39 V.NORDENSKIÖLD, Erland. Indianer und Weisse in Nordostbolivien. Stuttgart: Strecker und Schröder, 1922; WEINSTEIN, Barbara. A borracha na Amazônia: expansão e decadência 1850-1920. Tradução de Lólio Lourenço de Oliveira. São Paulo: Hucitec, EDUSP, 1993; RENARD-CASEVITZ, FranceMarie. História Kampa, Memória Ashaninca. In: CUNHA, Manuela Carneiro da (Org.). História dos índios no Brasil. Tradução de Beatriz Perrone-Moisés. São Paulo: Companhia das Letras, Secretaria Municipal de Cultura, Fapesp, 1998 [1992]. p. 197-212. 
transformação do cenário regional foi testemunhada de modo direto por vários sul-americanistas que, por ela, responsabilizaram seringalistas e, principalmente, seringueiros ${ }^{40}$. Nordenskiöld ${ }^{41}$ denunciou que "a febre da borracha" tinha, de forma direta ou indireta, devastado a maior parte do oeste da Bolívia e tornou público que o processo de obtenção da borracha contava com mão de obra indígena escravizada. Para dar ao leitor a dimensão da tragédia que se passava nos seringais, recordou as palavras, ouvidas de um branco estabelecido há muito na região Amazônica e para quem a indignação do sul-americanista soava descabida: "Ohne Indianer keine Kautschukindustrie!" [Sem índios, sem indústria da borracha! ${ }^{42}$.

Em torno dos afluentes do Juruá não deixava também de valer aquela máxima. Capistrano de Abreu aludiu à grave ameaça que os exploradores da borracha representavam para os povos pano na seguinte passagem de seu rã-txa $h u-n i-k u-\tilde{l}$ :

Nas linguas estudadas pelos missionarios [Conivo, Sipibo e Pano], o accento cáe na penultima. Continuarão no mesmo rumo? [...] Os seringueiros terão cuidado de sepultar a resposta no limbo dos "ignorabimus". 43

Incapazes, naturalmente, de fazer frente aos ditames do capitalismo internacional, os sul-americanistas tinham, no entanto, a possibilidade (e, na verdade, se viam na obrigação) de resgatar a tempo do "limbo dos "ignorabimus'” questões relativas às línguas e culturas indígenas.

\section{0 trabalho de campo e o de gabinete: tarefas complementares}

Versados em etnografia e lingüística, os sul-americanistas sérios de forma alguma se confundiam com os aventureiros, via-

40 Cf., por exemplo, KISSENBERTH, Wilhelm. Über die hauptsächlichsten

Ergebnisse der Araguaya-Reise. Zeitschrift für Ethnologie, v. 44, 36-59, 1912. p. 38 e a resenha de Ehrenreich a Voyage au Xingu e Voyage au TocantinsAraguaya de Henri Coudreau, Cx. 68: "Resenhas", APE.

41 NORDENSKIÖLD, Erland. Indianer und Weisse in Nordostbolivien. Stuttgart: Strecker und Schröder, 1922. p. 3.

42 Ibid p. 113. trad. Beatriz Christino.

43 ABREU, João Capistrano de. rã-txa $h u-n i-k u-\tilde{l}$ - a língua dos caxinauás do rio Ibuaçú, affluente do Murú (Prefeitura de Tarauacá). 1.ed. Rio de Janeiro: Typografia Leuzinger, 1914. p. 29. Negrito adicionado. 
jantes sem condições ou preocupação de agir com rigor científico que rumavam para as selvas ou para os sertões sul-americanos e esperavam ganhar fama com livros sobre os percalços mirabolantes de suas expedições.

Ainda que as expedições com objetivos científicos a lugares desconhecidos trouxessem inegável prestígio aos autênticos pesquisadores-viajantes, as viagens não chegavam sequer a constituir uma condição necessária para que um intelectual figurasse entre os sul-americanistas do primeiro time nos anos 1890-1929. Isso porque, a forma de tratamento dos dados assumia então, no julgamento da relevância científica de um trabalho, maior peso do que a recolha in loco dos mesmos. De maneira geral, só mereciam sanções positivas da comunidade dos sul-americanistas os que dominavam a literatura específica e valiam-se dos conceitos e da metodologia consagrados. Parte dos referenciais teórico-metodológicos partilhados pelos sulamericanistas de então - e a maneira como se apresentam no rã-txa $h u-n i-k u-\tilde{\imath}$ de Capistrano de Abreu - serão focalizados no próximo item.

Tornou-se evidente, assim, que carecia de verdadeiro valor o trabalho de campo que não fosse seguido por um trabalho de gabinete respeitável. Dentre os textos que indicaram essa visão, encontram-se recortes de dois jornais alemães que noticiaram os planos do sueco Gustaf Bolinder (1888-1957) de excursionar pela segunda vez pela Colômbia. Não por acaso, ambos os textos sublinharam que a nova viagem teria início no momento em que Bolinder concluísse a publicação dos resultados de sua primeira expedição $^{44}$.

Nessa mesma linha, Hestermann enalteceu o legado de Koch-Grünberg para a Sul-americanística fazendo referência às duas faces complementares do trabalho etnográfico-lingüístico. Ele lembrou que o autor de Vom Roroima zum Orinoco fora tão exímio no trabalho de campo, quanto analisando o material que colhera. Em função disso, Koch-Grünberg teria recebido, desde muito, "die Annerkennung seiner Forschungsarbeit, der im Felde und der am Gelehrtentisch" [o reconhecimento por seu trabalho de pesquisa, no campo e na escrivaninha de erudito] ${ }^{45}$.

44 Cf. recorte não-identificado e recorte, segundo anotação manuscrita de Koch-Grünberg, de artigo publicado no jornal Stuttgarter Tagblatt em 25 de fevereiro de 1917, Série "Correspondência”, Pasta 22, ATKG.

45 HESTERMANN, P. Ferdinand. Einleitung des Herausgebers. KOCHGRÜNBERG, Theodor. 1928. Vom Roroima zum Orinoco. Ergebnisse einer Reise in Nordbrasilien und Venezuela in den Jahren 1911-1913. Vierter Band. Sprachen. Stuttgart: Strecker und Schröder, 1928, S. XI-XII, S. XII. Negritos adicionados, trad. Beatriz Christino. 
Capistrano de Abreu, que nunca empreendeu uma viagem de pesquisa e serviu-se do auxílio de informantes nativos enviados para a sua companhia, ganhou admiração por seu trabalho de gabinete. Parte das horas passadas em sua "rede-escrivaninha" de erudito foram dedicadas à tradução para o português de textos de Karl von den Steinen (1855-1929) e de Paul Ehrenreich (1855-1914), que renovaram a etnografia sul-americana. Ele compôs uma versão em nossa língua dos capítulos iniciais de Durch Central-Brasilien ${ }^{46}$ que, com o título de "Na gema do Brasil", começou a ser publicada no número 203 da Gazeta de Notícias, em 22 de julho de 1888. A impressão do trabalho teve continuidade nos números 204 a $215,217,218,220,222,225,231,254,261,264,267$ e foi interrompida no 302 , de 29 de outubro do mesmo ano ${ }^{47}$. A parte traduzida (as primeiras 115 páginas do original) ganhou nova publicação como apêndice a Do Rio de Janeiro a Cuyabá do norte-americano Herbert Smith (1851-1919), texto também passado por Capistrano de Abreu para o Português. Sua atuação como tradutor tornou acessíveis ao público brasileiro, ainda, dois textos particularmente relevantes de Ehrenreich: "Über die Einteilung und Verbreitung der Volkerstämme Brasiliens nach dem gegenwärtigen Stande unserer Kenntnisse”, saído na Pettermanns Mitteilung, 37 em 1891 e "Die Ethnographie SüdAmerikas im Beginn des XX. Jahrhunderts", saído em Archiv für Anthropologie, $3 \mathrm{em} \mathrm{1904.} \mathrm{A} \mathrm{primeira} \mathrm{dessas} \mathrm{traduções}$ foi estampada no Jornal do Commercio em junho de $1891^{48}$ e posteriormente reproduzida na Revista da Sociedade de Geographia do Rio de Janeiro, tomo VIII, 1892. A tradução de "Die Ethnographie [...]" saiu na Revista do Instituto Histórico de São Paulo, vol. $\mathrm{XI}^{49}$, e na coletânea Brasil Antigo, Atlantide e Anti-

46 STEINEN, Karl von den. Durch Central-Brasilien Expedition zur Erforschung des Schingú im Jahre 1884. Leipzig: F.A. Brockhaus, 1886.

47 Cf. ABREU, João Capistrano de. Do Rio de Janeiro a Cuiabá. Notas de um naturalista. Prefácio e notas a Smith, Herbert H. Com um capítulo de Carlos von den Steinen sobre a capital de Matto Grosso.. Cayeiras, SP; Rio de Janeiro: Melhoramentos, 1922. p. 331.

48 Cf. ABREU, João Capistrano de. rã-txa $h u-n i-k u-\tilde{l}$ - a língua dos caxinauás do rio Ibuaçú, affluente do Murú (Prefeitura de Tarauacá). 1.ed. Rio de Janeiro: Typografia Leuzinger, 1914. p. 3.

49 EHRENREICH, Paul. A ethnografia da America do Sul ao começar o Seculo XX. Tradução de Capistrano de Abreu. Revista do Instituto Historico e Geographico de São Paulo, v. 11, p. 280-305, 1907a. 
guidades Americanas ${ }^{50}$. Uma versão mais concisa - desprovida dos parágrafos iniciais - saiu no Almanack Brasileiro Garnier de 1907, batizada de "Ethnographia selvagem" 51.

Além de ter sido um leitor atento e tradutor cuidadoso de von den Steinen e de Ehrenreich, Capistrano de Abreu dialogou efetivamente com esses cientistas. É o que revela, por exemplo, a carta transcrita abaixo, em que von den Steinen justifica para o colega brasileiro a forma de organização de seu Die Bakairi Sprache $^{52}$, publicado pouco antes.

Lieber Sr. Capistrano,

Ich habe Ihnen gestern geschrieben, dass ich für die nächste Zeit hinaus bei der Ethnologie, etc. der II ten. Expedition festsitze, dennoch möchte ich noch einmal speciell hierauf verweisen weil Sie mich fragen, ob ich einen Band Ihres grossen Werkes übernehmen wolle. Ich habe leider nicht die Zeit - ich bin vorläufig noch beim Schingu und gehe darauf sofort zu anderen Arbeiten über, die schon lange warten.

Ihnen ist aufgefallen dass ich die "Grundsprache“ und den comparativen Teil vor der Bakairi-Grammatik bringe. Ich wusste mir aber nicht anders zu helfen, weil ich glaube und zu beweisen suche, dass man die Bakairi-Sprache nur durch Vergleichung verstehen lernt; jedes einzeln Karaiben-Idiom führt, ohne comparatives Studium, zu fälschen Schlüssen. ${ }^{53}$

[Caro Sr. Capistrano

Escrevi ontem dizendo que me encontro ocupado com a etnologia, etc. da II Expedição; no entanto, quero dizê-lo outra vez,

50 EHRENREICH, Paul. A ethnografia da America do Sul ao começar o Seculo XX. In: DOMINGOS, Jaguaribe. Brasil Antigo, Atlantide e antiguidades americanas. Tradução de Capistrano de Abreu. 2.ed. São Paulo: Casa Garraux, 1910. p. 177-207.

51 EHRENREICH, Paul. Ethnographia selvagem. In: ALMANACK Brasileiro Garnier para o ano de 1907. Tradução de Capistrano de Abreu. Rio de Janeiro: Livraria Garnier, 1907. p. 79-98.

52 STEINEN, Karl von den. Die Bakairi Sprache. Leipzig: K. F. Koehler's Antiquarium, 1892.

53 Carta de Karl von den Steinen a Capistrano de Abreu, 17 de janeiro de 1893. In: ABREU, João Capistrano de. Correspondência de Capistrano de Abreu. 2.ed. Rio de Janeiro: Civilização Brasileira; Brasília: Instituto Nacional do Livro, 1977. v. 3, p. 126, itálicos originais. (1ª edição de 1954). 
porque o Sr. me pergunta se posso encarregar-me de um volume da sua grande obra. Infelizmente falta-me tempo - por enquanto ainda estou no Xingu, e em seguida passarei a outros trabalhos, que já esperam há muito tempo.

O Sr. observa que, em meu trabalho, a "língua básica" e a parte comparativa vêm antes da gramática bacairi. É que não encontrei outra solução, pois creio e tento demonstrar que só se conseguirá compreender o idioma bacairi, estabelecendo-se comparação; sem o estudo comparativo cada um dos idiomas caraíbas levará a conclusões erradas.] $]^{54}$

A "grande obra" mencionada corresponde a uma coleção de estudos monográficos sobre o Brasil idealizada por Capistrano de Abreu. Nos planos do historiador brasileiro, estava um volume sobre etnografia indígena que deveria ficar a cargo de von den Steinen. Como se vê, o pesquisador alemão frustrou tais esperanças usando como alegação a extensão de seu trabalho de gabinete ainda por realizar.

\section{0 pesquisador tem de ser "o homem certo"}

A complementaridade entre o trabalho de campo e o de gabinete (nem sempre empreendidos por um mesmo estudioso) levava os sul-americanistas em foco a relativizarem o papel das viagens de pesquisa. Segundo sua visão, as expedições até as aldeias não seriam imprescindíveis para o desenvolvimento de análises lingüísticas de qualidade. Desde que um pesquisador bem preparado voltasse sua atenção para um informante capacitado, pouco importava o local em que se procedia à recolha dos dados. Simetricamente, fadava-se ao fracasso a saída a campo de pessoas sem condições de realizar investigações lingüisticas.

De acordo com uma afirmação de Hestermann (p.648) ${ }^{55}$, só autênticos sul-americanistas estariam habilitados a empreender o exame minucioso e profundo de cada língua e de cada

54 Trad. de José Honório de Abreu. In: ABREU, João Capistrano de.

Correspondência de Capistrano de Abreu. 2.ed. Rio de Janeiro: Civilização Brasileira; Brasília: Instituto Nacional do Livro, 1977. v. 3, p. 127-8, nota 1, itálicos originais. (1ª edição de 1954).

55 HESTERMANN, P. Ferdinand. Die Pano-Sprachen und ihre Beziehungen. Verhandlungen des XVI Internationalen Amerikanisten-Kongresses Wien 9. bis 14. September 1908. Zweite Hälfte. Wien und Leipzig: A. Hartleben's, 1910. p. 645-650. 
dialeto, palavra por palavra e forma por forma, que se fazia necessário para o avanço da lingüística sul-americana. Tais investigações demandavam obrigatoriamente a adoção de um sistema rigoroso de transcrição dos dados lingüísticos e a acurada comparação entre os dados da língua em foco e aqueles pertencentes às demais línguas conhecidas da mesma família. Caíam em total descrédito os pesquisadores que buscavam semelhanças entre línguas americanas e línguas de outros continentes, à procura de remotos parentescos entre grupos humanos.

Era consenso entre os sul-americanistas sérios que as narrativas tradicionais representavam o melhor campo para estudos gramaticais, pois encerrariam a única via de acesso à língua "real". Para além de servir de material de controle para as listagens lexicais e para as descrições de fenômenos morfológicos previamente estabelecidas, esses textos descortinavam aos estudiosos novas (e mais reais e fascinantes) dimensões da língua. Nesse sentido, correspondiam ao melhor guia para conduzir os sul-americanistas daquele período a um de seus maiores objetivos, no caso das análises lingüísticas: a postulação de descrições adequadas às características das línguas em estudo e libertas dos modelos eurocêntricos de linguagem.

Em seu rã-txa $h u-n u-k u-\tilde{\imath}$, Capistrano de Abreu atendeu admiravelmente às quatro diretrizes expostas acima. A precisão com que ele transcreveu as palavras caxinauás foi louvada, como veremos adiante, por Hestermann ${ }^{56}$. Ao longo da seção de descrição gramatical da obra e, especialmente no que tange à descrição dos paradigmas verbais, ele contrastou o caxinauá com outras línguas pano, baseando-se em informações colhidas no Vocabulario Castellano-Quechua-Pano do franciscano Manuel Navarro, no Diccionario Sipibo, de autoria de um missionário franciscano desconhecido e editado por von den Steinen em 1904 e na obra de Frei Agustín Alemany Diccionario Castellano-Shipibo y Elementos de Gramatica. Fica evidente, acima de tudo, que Capistrano de Abreu pôs em prática uma lingüística a partir do texto, ideal verdadeiramente caro aos sul-americanistas dos anos 1890-1929, mas concretizado, de fato, por poucos deles. Assim como as milhares de palavras constantes do seu "Vocabulario caxinauá-brasileiro", suas observações de caráter gramatical tiveram origem na consideração de mais de uma centena de textos tradicionais reunidos por ele e acompanhados de rigorosa tradução interlinear.

56 HESTERMANN, P. Ferdinand. Die Schreibweise der Pano-Vokabularien mit Benutzung von Angaben J. Capistrano de Abreu's und M. Said Ali Ida's. Journal de la Société des Américanistes de Paris, v. 11, p. 21-33, 1914. 
Por fim, marcam presença no rã-txa $h u-n i-k u$ - $\tilde{\text { s soluções }}$ descritivas que se afastam dos modelos fornecidos pela tradição gramatical greco-latina ${ }^{57}$. Capistrano propôs, por exemplo, uma divisão dos sufixos do caxinauá em duas subcategorias: a dos "suffixos lexicos" e a dos "suffixos syntacticos". Os primeiros corresponderiam àqueles que "modificam o sentido primitivo"58 da palavra a que são acrescidos e não revelariam qualquer ligação com mecanismos de caráter sintático, como "bã i” indicativo de "partida ou locomoção" ou "kãi-kãi" que traria a noção de "quotidianamente ou totalmente" 59 . Os "suffixos syntacticos", por sua vez, receberam tal denominação "porque não modificam a significação do vocabulo e só apparecem nas orações”60. Vale dizer, sem interferir na semântica da palavra a que se uniam, agiriam no domínio da oração, fosse identificando relações entre os constituintes da sentença, indicando tempo verbal ou estabelecendo as distinções entre declarações e interrogações. A maneira como Capistrano de Abreu descreveu o sistema de marcação casual caxinauá revela particularmente uma preocupação de captar a natureza da língua em exame. 0 pesquisador brasileiro registrou que os pronomes pessoais caxinauás declinavam-se de modo sistemático, havendo uma diferenciação inequívoca entre uma forma nominativa e uma acusativa. Os nomes, por sua vez, apresentariam um caso com as funções de nominativo, genitivo e vocativo e "caracteriza[do] habitualmente pelo final nasalado". Nas manifestações do outro caso, que englobaria o acusativo e as construções com posposições, a vogal final nasalizada estaria geralmente ausente. Postulando um nominativo marcado oposto a um acusativo não-marcado, Capistrano de Abreu chegou a uma situação sem qualquer paralelo nas línguas européias mais conhecidas. Além disso, ele afirmou que os nomes poderiam também surgir desprovidos de terminação casual, o que denominou de "forma indifferente em que podem ser sujeito ou objecto"61.

57 Para uma abordagem detalhada das soluções descritivas presentes no rãtxa $h u-n i-k u-\tilde{\imath}$, v. CHRISTINO, Beatriz. A rede de Capistrano de Abreu: uma análise historiográfica do rã-txa $h u-n i-k u-\tilde{l}$ em face da Sul-Americanística dos anos 1890-1929. 232 f. Tese (Doutorado em Semiótica e Lingüística Geral) - Faculdade de Filosofia, Letras e Ciências Humanas, Universidade de São Paulo, São Paulo, 2006.

58 ABREU, João Capistrano de. rã-txa $h u-n i-k u-\tilde{l}$ - a língua dos caxinauás do rio Ibuaçú, affluente do Murú (Prefeitura de Tarauacá). 1.ed. Rio de Janeiro: Typografia Leuzinger, 1914. p. 18.

59 Ibid. p. 23.

60 Ibid. p. 29.

61 Ibid. p. 548. 
Como demonstrou Capistrano de Abreu, um pesquisador capaz de pôr em prática as diretrizes teórico-metodológicas norteadoras do trabalho dos sul-americanistas podia realmente coletar dados a muitas centenas de quilômetros das aldeias indígenas. Por isso, Koch-Grünberg sugeriu que pesquisadores tarimbados poderiam se valer da ajuda de índios que se achavam nas prisões ${ }^{62}$. Reunir dados tanto lingüísticos quanto etnográficos com o auxílio de informantes nas cidades mostrava-se uma tarefa a que Koch-Grünberg atribuía grande relevância. Em maio de 1905, ele juntou dados do makuxi e do wapixana em Manaus, graças à colaboração do cacique makuxi Ildefonso e de seus companheiros, que pretendiam se encontrar com o governador da então província do Amazonas (p.13) ${ }^{63}$. KochGrünberg alimentou esperanças de que as comemorações do primeiro centenário da Independência do Brasil convertessem o Rio de Janeiro em um local especialmente promissor como fonte de bons informantes. Ele imaginava que o governo brasileiro, no âmbito daqueles festejos, promoveria a ida à capital de índios de diversos grupos. Além disso, acreditou que seria convidado para as festividades por conta de seu lugar de destaque nos estudos da etnografia e lingüística brasileiras. Desse modo, vislumbrou a possibilidade de obter uma preciosa e variada documentação etnográfico-lingüística sem nenhum grande deslocamento e em um curto período ${ }^{64}$.

Para a decepção de Koch-Grünberg, não houve qualquer interesse das autoridades brasileiras em viabilizar sua vinda ao país naquela ocasião, ainda que o pesquisador alemão tenha mobilizado sua rede de contatos científicos no Brasil para interceder a seu favor. Capistrano de Abreu engajou-se particularmente na cruzada em busca de financiamento oficial para o companheiro de especialidade, o que permanece registrado na carta em que o missionário beneditino Padre Adalbert Kaufmehl teve o desprazer de comunicar ao compatriota que uma resposta afirmativa nunca viria. Ali podemos ler: "Capistrano de Abreu hat persönlich mit mehreren Ministern der Bundesregierung Rücksprache gehabt, [...] aller Bescheid war immer: „Não ha verba para isso" [Capistrano de Abreu conferenciou pesso-

62 Cf. carta a Hermann Schmidt, sem data, Série “Correspondência”, Pasta 6, ATKG.

63 Cf. KOCH-GRÜNBERG, Theodor und Georg Hübner. Die Makuschí und Wapischána. Zeitschrift für Ethnologie, v. 40, p. 1-44, 1908.

64 Cf. cartas a Paul Rivet, de 27 de novembro de 1920, e a Karl Sapper, de 3 de outubro de 1920 (ambas arquivadas na Pasta 29) e a J. Michaelis, de 21 de julho de 1921, Pasta 31, Série "Correspondência”, ATKG. 
almente com vários ministros do Governo [...] a resposta foi sempre a mesma: "Não ha verba para isso"] ${ }^{65}$.

Não deve nos causar espanto o empenho de Capistrano de Abreu. Afinal, ao que tudo indica, o autor do rã-txa $h u-n i-k u-\tilde{l}$ representava o principal interlocutor brasileiro de Koch-Grünberg. Apesar da interrupção provocada pela primeira guerra mundial, estabeleceu-se entre eles um intercâmbio científico duradouro em que não se nota qualquer traço de subserviência intelectual. Vale dizer, os dois estudiosos dialogavam de igual para igual e fica afastada de todo a idéia de que a Alemanha (ou a Europa) correspondesse, na geografia da produção científica em etnografia e lingüística indígenas, ao centro e o Brasil (ou a América do Sul), à periferia.

Com freqüência, Koch-Grünberg fez menção ao caráter admirável da obra de Capistrano de Abreu sobre a língua e os mitos caxinauás, da qual retirou treze textos para a sua coletânea de narrativas tradicionais sul-americanas, ${ }^{66}$ e que considerava um modelo a ser seguido. Escrevendo a Curt Nimuendajú (1883-1945), ele recorreu ao exemplo de Capistrano de Abreu para provar que o valor de uma análise etnográfico-lingüística em nada dependia da efetiva presença do pesquisador em uma comunidade indígena. Assim, frisou que Nimuendajú poderia muito bem trabalhar com informantes residentes em Belém do Pará e chegar a ótimos resultados.

Aber auch in Para selbst können Sie wohlig aller Ruhe und Bequemlichkeit Indianerstudien treiben. Es gibt doch sicherlich dort, ebenso wie in Manaos, unter den Bediensteten manchen Indianer aus dem Innern, der neben dem Portugiesischen noch seine Stammessprache spricht. Man muss diese Leute nur zum Sprechen und Erzählen bringen, und dazu sind Sie der rechte Mann. Denken Sie an Capistrano de Abreu, der sein wundervolles und in Südamerika so ziemlich einzig dastehendes Werk auch nicht am oberen Juruá zusammengestellt hat!

[Mas também no próprio Pará [Belém] o Sr. pode empreender estudos indígenas com toda a tranqüilidade e conforto. Há certamente lá, assim como em Manaos, entre os criados algum

65 Carta de P. Adalbert Kaufmehl a Theodor Koch-Grünberg, Rio de Janeiro, 10 de abril de 1921, Série “Correspondência”, Pasta 30, ATKG, trad. Beatriz Christino.

66 KOCH-GRÜNBERG, Theodor. Indianermärchen aus Südamerika. Jena: Eugen Diedrichs, Zweite Ausgabe, 1927 [1920]. 
índio do interior, que paralelamente ao Português ainda fala a língua de sua tribo. É preciso apenas levar essa gente a falar e contar e, para isso, o Sr. é o homem certo. Pense em Capistrano de Abreu, que também não reuniu no Alto Juruá sua obra maravilhosa e na América do Sul realmente singular! ${ }^{67}$

Os indícios inequívocos de que Koch-Grünberg incluía Capistrano de Abreu no seleto grupo dos "homens certos" para efetuar e analisar registros etnográfico-lingüísticos não se restringiram à esfera das comunicações privadas. Serve como comprovação disso, a resenha do rã-txa $h u-n i-k u-\tilde{l}$ saída de sua pena e publicada em Anthropos:

Ein in der südamerikanischen Ethnographie und Linguistik fast einzigartiges Werk von hohem wissenschaftlichem Wert. Das größte und beste Material, das jemals über eine südamerikanische Indianersprache veröffentlicht wurde $[\ldots]^{68}$

Obra de alto valor scientifico, quasi sem paralelo na linguistica e ethnographia sul-americanas. 0 maior e melhor material que jámais se publicou sobre lingua sul-americana de indios [... $]^{69}$

Com as palavras de Koch-Grünberg acima transcritas concordavam os demais sul-americanistas de ponta. Tão logo a obra de Capistrano de Abreu sobre o caxinauá ganhou divulgação, Rivet dedicou-lhe uma resenha em que foram enfatizadas a abrangência da recolha e a precisão na análise dos fenômenos lingüísticos. Uma e outra colocariam o caxinauá no (reduzido) rol das línguas sul-americanas bem descritas, com a invejável posição de melhor descrita.

67 Carta de Theodor Koch-Grünberg a Curt Nimuendajú, 16 de setembro de 1920, Série “Correspondência”, Pasta 29, ATKG. Negritos adicionados, trad. Beatriz Christino.

68 Série "Resenhas de autoria de Koch-Grünberg", ATKG, negritos adicionados. Resenha publicada em Anthropos, v. 14/15, 1917/1918. Cad. 5/6, e mencionada na carta de P. W. Schmidt a Theodor Koch-Grünberg de $1^{\circ}$ de dezembro de 1919 e na carta de Theodor Koch-Grünberg a Capistrano de Abreu de 8 de janeiro de 1920, respectivamente, Pasta 27 e Pasta 28, Série "Correspondência”, ATKG.

69 Koch-Grünberg apud ABREU, João Capistrano de. rã-txa $h u-n i-k u-\tilde{l}$ - a língua dos caxinauás do rio Ibuaçú, affluente do Murú (Prefeitura de Tarauacá). Com as emendas do autor e um estudo do Prof. Theodor KochGrünberg. 2.ed. Rio de Janeiro: Sociedade Capistrano de Abreu; Livraria Briguiet, 1941. p. 633. Negritos adicionados, trad. de Manuel Said Ali. 
son livre est certainement un des documents linguistiques le plus importants que nous possédons jusqu'à ce jour sur les langues sud-américaines.

[...] Grâce à Capistrano de Abreu, ce dialecte [caxinauá] est certainement maintenant celui sur lequel nous possédons le matériel le plus complete et le meilleur.

L'ouvrage est divisé en quatre parties. La première est une excellente étude grammaticale du Caxinauá. La deuxième ne renferme pas moins de 5926 phrases, dont la réunion forme un texte ethnographique des plus précieux.

\section{$[\ldots]$}

[...] En le signalant tout particulièrement à leur attention, je ne puis qu'émettre le voeu que l'exemple de Capistrano de Abreu soit suivi par d'autres chercheurs sud-américains. ${ }^{70}$

Mais de dez anos depois de sua publicação, o trabalho de Capistrano continuaria inigualável, na visão de Rivet. Num artigo sobre "Les dialectes Pano du haut Juruá et du haut Purús", ele e Constantino Tastevin asseguraram que, enquanto sobre as línguas pano "yaminawa, kanawary e amahuaka” a documentação disponível não passava de vocabulários de pequena extensão, sobre o caxinauá

[...] heuresement, grâce a un savant linguiste brésilien, Capistrano de Abreu, nous possédons, depuis quelques années, une étude, admirable de précision et aussi complete qu'on peut le désire. $(p .814)^{71}$

Para Ferdinand Hestermann, que Capistrano de Abreu julgava "um dos mestres" no estudo comparativo das línguas pano $^{72}$, o rã-txa $h u-n i-k u-\tilde{\imath}$ corresponderia ao único trabalho de

70 RIVET, Paul. Bulletin Critique - Capistrano de Abreu (J.). rã-txa hu-ni-ku-ĩ, a lingua dos Caxinauás do rio Ibuaçu affluente do Muru (prefeitura de Taranacá) [rã-txa hu-ní-ku-ĩ , la langue des Caxinauás du rio Ibuaçu, affluent du Muru (préfecture de Tarauacá)]. Rio de Janeiro, 1914. v. 1, 630 p.; Journal de la Société des Américanistes de Paris, v. 11, p. 333, 1914. Negritos adicionados.

71 RIVET, Paul et Tastevin, C. Les dialects Pano du haut Juruá et du haut Purus. Anthropos, v. 22, p. 811-827, 1927.

72 ABREU, João Capistrano de. rã-txa $h u-n i-k u-\tilde{l}$ - a língua dos caxinauás do rio Ibuaçú, affluente do Murú (Prefeitura de Tarauacá). 1.ed. Rio de Janeiro: Typografia Leuzinger, 1914. p. 625. 
real valor na área da lingüística sul-americana escrito em língua portuguesa. Sua opinião data da segunda metade da década de 1920 e é taxativa: "Nur ein Werk in portugiesischer Sprache ragt außergewöunlich hervor und darf nicht übergangen werden: Das Werk über die Kaschinaua von DE ABREU (Rio de Janeiro 1914)." [Somente uma obra em língua portuguesa se destaca extraordinariamente e não deve ser deixada para trás: a obra sobre os caxinauás de DE ABREU.... $]^{73}$. 0 rã-txa $h u-n i-k u-\tilde{\imath}$ não seria singular apenas em meio à tradição descritiva escrita em nossa língua, visto que Hestermann qualificou-o também como "das bedeutsamste Werk über die Pano-Sprachen" [a obra mais significativa sobre línguas pano $]^{74}$. Lançando mão das provas de impressão daquela obra, Hestermann sublinhou o cuidado com que o autor brasileiro grafara as palavras do caxinauá, que reputava único na literatura sobre as línguas da família pano. Segundo ele, apenas o pesquisador brasileiro alcançara uma transcrição consistente e precisa dos dados lingüísticos, habilitada a subsidiar estudos comparativos confiáveis.

Como primeiro apêndice a seu artigo avaliando a forma de transcrição nos vocabulários de línguas da família pano ${ }^{75}$, Hestermann reproduziu integralmente um esboço fonético do caxinauá escrito em alemão por Manuel Said Ali (1861-1953), em outubro de 1912, tendo como base a descrição de Capistrano de Abreu. Um segundo apêndice estampou o conteúdo de um manuscrito do próprio Capistrano de Abreu sobre a fonética do caxinauá. Redigido em português, o texto contou com uma página e meia e foi acompanhado da advertência em nota de rodapé de que aquela abordagem deveria corresponder à das linhas iniciais do rã-txa hu-ni-ku-ĩ. Não se descartava, no entanto, a possibilidade de a versão definitiva conter modificações. Com efeito, em vários pontos, o texto publicado em livro pela Tipographia Leuzinger diverge do incluso no artigo de Hestermann.

73 HESTERMANN, P. Ferdinand. Koch-Grünberg zum ehrenden Gedenken. Die Linguistik Südamerikas - besonders in Deutschland - von der ersten Xingú bis zur letzten Orinoko Expedition. Folia Ethno-glossica, Blätter für Völkerkunde, Sprachwissenschaft, Verwandtes, v. 1, p. 1-4, 1927. p. 3, nota 1, trad. Beatriz Christino.

74 HESTERMANN, P. Ferdinand. Die Schreibweise der Pano-Vokabularien mit Benutzung von Angaben J. Capistrano de Abreu's und M. Said Ali Ida's. Journal de la Société des Américanistes de Paris, v. 11, p. 21-33, 1914. p. 21, trad. Beatriz Christino.

75 HESTERMANN, P. Ferdinand. Die Schreibweise der Pano-Vokabularien mit Benutzung von Angaben J. Capistrano de Abreu's und M. Said Ali Ida's. Journal de la Société des Américanistes de Paris, v. 11, p. 21-33, 1914. 
0 prestigiado Hestermann deixou bem claro, ainda, que Capistrano de Abreu tinha sido o "homem certo" para analisar a cultura espiritual dos caxinauás a partir dos seus mitos e narrativas tradicionais. Em sua visão, o rã-txa $h u-n i-k u-\tilde{\imath}$ afigurava-se indiscutivelmente como uma obra clássica também nesse aspecto. Quando resenhou o segundo volume de Vom Roroima zum Orinoco, louvou o exame dos mitos taulipáng e arekuná ali empreendido por Koch-Grünberg colocando-o lado a lado com o trabalho do autor brasileiro:

Hatte jüngst Capistrano de Abreu in seinem geradezu klassischen Werke bezüglich der Kaschinaua uns so intim orientiert über und durch alle Faltungen des Geisteslebens, so bietet uns hier Prof. Koch-Grünberg das volle Gegenstück.

[Recentemente Capistrano de Abreu nos orientou, na sua obra verdadeiramente clássica acerca dos caxinauás, tão intimamente por entre cada reentrância da vida espiritual, agora o Prof. Koch-Grünberg nos oferece aqui o perfeito equivalente. $]^{76}$

\section{Conclusão}

As incontáveis horas que Capistrano de Abreu passou analisando línguas indígenas não acarretaram sua exclusão do debate científico. Na verdade, conduziram-no à condição de sul-americanista dos mais respeitados pela comunidade internacional de especialistas, cujos ideais de ciência ele punha em prática.

Sua obra sobre a língua e os mitos caxinauás foi então recebida como uma contribuição especialmente valiosa na luta para registrar as tão ameaçadas culturas indígenas. 